\title{
Repeated in vivo determinations of bone mineral density during parathyroid hormone treatment in ovariectomized mice
}

\author{
N Andersson ${ }^{1,2}, M$ K Lindberg ${ }^{3}, C_{\text {Ohlsson }}^{3}$, K Andersson $^{1}$ \\ and B Ryberg ${ }^{\mathbf{1}}$ \\ ${ }^{1}$ AstraZeneca R\&D, Mölndal, Sweden \\ ${ }^{2}$ Institute of Physiological Sciences, Department of Pharmacology, Lund University, Lund, Sweden \\ ${ }^{3}$ Department of Internal Medicine, Sahlgrenska University Hospital, Göteborg, Sweden \\ (Requests for offprints should be addressed to Niklas Andersson, AstraZeneca R\&D Mölndal, S-431 83 Mölndal, Sweden; \\ Email: niklas.andersson@astrazeneca.com)
}

\begin{abstract}
The recent development of different genetically modified mice with potentially interesting bone phenotypes has increased the demand for effective non-invasive methods to evaluate effects on bone of mice during growth and development, and for drug evaluation. In the present study, the skeleton was analyzed by repeated in vivo scans using dual energy X-ray absorptiometry (DXA) and peripheral quantitative computed tomography (pQCT). Ovariectomized (ovx) mice treated with parathyroid hormone (PTH) were used as an animal model to evaluate these two techniques at different times after the onset of treatment. Female mice ( 6 weeks of age) were allocated randomly to four groups: (1) sham-operated+vehicle; (2) ovx + vehicle; (3) sham-operated + PTH(1-84) $150 \mu \mathrm{g} /$ kg per day; (4) ovx + PTH. Six weeks after ovariectomy the drug treatment began and was continued for 8 weeks. The total body bone mineral content (BMC) and total body areal bone mineral density (BMD) were measured by DXA. Ovariectomy reduced total body BMC and total body areal BMD by $6 \cdot 2 \pm 1 \cdot 7 \%$ and $2 \cdot 6 \pm 0 \cdot 9 \%$
\end{abstract}

respectively. No effect of PTH on total body BMC was seen during the treatment period. The trabecular volumetric BMD was measured by pQCT. Ovariectomy reduced the trabecular volumetric BMD by $52 \pm 6 \cdot 7 \%$. The pQCT technique detected a clear effect on trabecular volumetric BMD after 2 weeks of PTH treatment (ovx $94 \pm 29 \%$ and sham-operated $46 \pm 10 \%$ more than vehicle-treated). The cortical bone was measured in a mid-diaphyseal pQCT scan of the tibia. Ovariectomy reduced the cortical BMC by $9 \pm 2 \%$. PTH treatment for 8 weeks increased cortical BMC in ovx mice.

In conclusion, the pQCT technique is more sensitive than the DXA technique in the detection of bone loss after ovariectomy and increased bone mass after PTH treatment in mice. Notably, the pQCT, but not the DXA, technique detected a dramatic effect as early as after 2 weeks of PTH treatment. Dynamic pQCT measurements will be useful for monitoring skeletal changes during growth and development, and for drug evaluation in mice.

Journal of Endocrinology (2001) 170, 529-537

\section{Introduction}

The recent development of different genetically modified mice with potentially interesting bone phenotypes has increased the demand for effective non-invasive methods to evaluate influences on the bones of mice during growth and development, and for drug evaluation. Dual-energy X-ray absorptiometry (DXA) and peripheral quantitative computed tomography (pQCT) are widely used noninvasive methods for determining bone mineral parameters in animals and humans. DXA can be used to estimate bone mineral content (BMC) and areal bone mineral density (BMD) of the entire body and of individual bones. However, the areal BMD measured with DXA should not be mistaken for the true volumetric BMD obtained with
pQCT. The pQCT can differentiate between cortical and trabecular bone and, in addition to density, it can measure parameters such as cortical area and cortical thickness (Rosen et al. 1995, Sandstedt et al. 1996, Windahl et al. 1999).

Parathyroid hormone $(\mathrm{PTH})$ is an anabolic agent that has attracted much attention as a potential candidate in the treatment of osteoporosis. Clinical trials have shown PTH, when administered intermittently, to have an anabolic effect on bone (Reeve et al. 1976, 1980). Intermittent PTH treatment is also effective in preventing ovariectomy-induced bone loss in rats (Dempster et al. 1993, 1995, Mitlak et al. 1996, Sato et al. 1997). Ovariectomy in the rat is an established animal model for studies on the prevention and treatment of osteoporosis. Estrogen 
deficiency results in an increase in bone turnover, with excess bone resorption, and significant loss of trabecular bone. In cortical bone, an increased bone turnover rate results in endosteal resorption; however, because this is compensated by periosteal growth, the net cortical bone loss is small (Shen et al. 1995, Yamauchi et al. 1995, Li et al. 1996, Bagi et al. 1997) The ovariectomy model is better established in rats than it is in mice (Turner et al. 1987, Broulik 1991, Edwards et al. 1992, Bain et al. 1993, Okada et al. 1998, Windahl et al. 1999), in which the effect of ovariectomy appears to be highly straindependent (Zeng et al. 1998). There is little information available on anabolic effects of PTH in mice (RihaniBisharat et al. 1998, Zeng et al. 1998, Stanislaus et al. 2000).

The aim of the present study was to compare the usefulness of the two non-invasive radiological techniques, pQCT and DXA, in the detection of early treatment effects on cortical and trabecular bone in mice. Ovariectomized (ovx) mice treated with PTH were used as an animal model to evaluate these two techniques at different time points after the onset of treatment.

\section{Materials and Methods}

\section{Animals}

Six-week-old, C57BL/6 female mice (Møllegaard's Breeding Center, Skensved, Denmark) were maintained on a 12-h light: $12-\mathrm{h}$ darkness cycle at $22{ }^{\circ} \mathrm{C}$ with food and water available ad libitum. The mice were divided into two groups: bilateral ovariectomies or sham operations were performed. Six weeks after surgery, the mice were divided into four treatment groups: (1) sham-operated+vehicle; (2) ovariectomized (ovx) + vehicle; (3) sham-operated+ PTH(1-84) $150 \mu \mathrm{g} / \mathrm{kg}$ per day; (4) ovx + PTH $(n=7-10$ mice/group). Body weights were determined at the start of drug treatment and every week thereafter. All animal procedures were reviewed and approved by the local animal welfare committee before the study started.

\section{Drug treatment}

Human recombinant $\mathrm{PTH}(1-84)$ was obtained from Allelix Biopharmaceuticals, Mississauga, Canada. All animals received daily subcutaneous (s.c.) injections $(5 \mathrm{ml} /$ $\mathrm{kg})$ of PTH $(150 \mu \mathrm{g} / \mathrm{kg})$ or the vehicle $(10 \mathrm{mmol} / 1$ citratebuffered saline, $\mathrm{pH} 5 \cdot 5)$ for 8 weeks. The mice were anesthetized with a mixture of ketamine $75 \mathrm{mg} / \mathrm{kg}$ (Ketalar, Parke-Davis, Barcelona, Spain) and medetomidine $1 \mathrm{mg} / \mathrm{kg}$ (Domitor vet., Orion, Espoo, Finland; intraperitoneal injection) during surgery and during all in vivo $\mathrm{X}$-ray measurements. After $\mathrm{X}$-ray measurements, an $\alpha 2$-antagonist (atipamezole, Antisedan vet., Orion), $1 \mathrm{mg} / \mathrm{kg}$ (s.c. injection), was administered to promote recovery and reduce sleeping time.

\section{Tissue collection}

After the cessation of treatment, the mice were anesthetized, subjected to cardiac puncture, and killed by cervical dislocation. The uterus was removed from each animal and weighed to confirm successful ovariectomy. Femora, tibiae and lumbar vertebrae L5 were removed, cleaned of soft tissue, fixed in 10\% formalin, and stored in $70 \%$ ethanol at $4{ }^{\circ} \mathrm{C}$.

\section{Dual-energy X-ray absorptiometry}

BMC and areal BMD were measured using the Norland pDEXA Sabre (Norland, Fort Atkinson, WI, USA). The software Sabre Research (v3.6) was used (Windahl et al. 1999). The machine was calibrated daily with a phantom provided by the manufacturer.

Total body BMC and total body areal BMD were measured in vivo 6 weeks after ovariectomy (at the start of drug treatment) and after 2, 4 and 8 weeks of drug treatment. Medium-resolution scans, with line spacing set at $0.05 \mathrm{~cm}$, were used. Three mice could be analyzed simultaneously in the same scan, therefore a mouse that was killed at the beginning of the experiment was included in each scan as an internal standard in order to avoid between-scan variations. The interassay coefficients of variation $(\mathrm{CV})$ for the DXA measurements were less than $5 \%$.

The femur, tibia and vertebrae L5 were measured $e x$ vivo on excised bones under a $15 \mathrm{~mm}$ layer of $70 \%$ ethanol. All excised bones were measured simultaneously in a single scan. High-resolution scans were used (line spacing $0.02 \mathrm{~cm}$ or $0.01 \mathrm{~cm})$.

\section{Peripheral quantitative computed tomography}

Tomographic measurements were made using the Stratec pQCT XCT Research M (Norland) specifically modified for use on small bone specimens (software version 5.4B; resolution $70 \mu \mathrm{m}$ ) (Rosen et al. 1995). The in vivo measurements were made on the tibia, for technical reasons.

In vivo measurements of the left tibia were made 6 weeks after surgery and after 2, 4 and 8 weeks of drug treatment. A metaphyseal pQCT scan was used to determine trabecular bone. The metaphyseal scan was positioned at $1 \%$ of the total length of the tibia distal to the growth plate. The trabecular bone region/compartment was defined as the density of the inner $45 \%$ of the scanned bone area. A mid-diaphyseal pQCT scan was made of the same tibia to determine the cortical BMD, the cortical cross-sectional area, the cortical thickness, the periosteal circumference, the endosteal circumference, the moment of resistance, and the cross-sectional moment of inertia.

Ex vivo measurements were performed on excised bones in order to enable us to correlate effects on the femur ex vivo with the effects on the tibia in vivo. Metaphyseal 
Table 1 Body weight, uterine weight and lengths of the femur and tibia in ovariectomized (ovx) and sham-operated (Sham) mice after 8 weeks of intermittent PTH treatment

\begin{tabular}{|c|c|c|c|c|}
\hline & $\begin{array}{l}\text { Sham } \\
\text { Vehicle }\end{array}$ & $\begin{array}{l}\text { Ovx } \\
\text { Vehicle }\end{array}$ & $\begin{array}{l}\text { Sham } \\
\text { PTH }\end{array}$ & $\begin{array}{l}\text { Ovx } \\
\text { PTH }\end{array}$ \\
\hline Body weight (g) & $23 \cdot 6 \pm 0 \cdot 6$ & $22 \cdot 9 \pm 0 \cdot 5$ & $24 \cdot 1 \pm 0 \cdot 6$ & $23 \cdot 8 \pm 0 \cdot 7$ \\
\hline Uterine weight (mg) & $74 \pm 7$ & $16 \pm 2^{*}$ & $98 \pm 13$ & $18 \pm 1^{*}$ \\
\hline Femur length $(\mathrm{mm})$ & $15 \cdot 5 \pm 0 \cdot 1$ & $15 \cdot 6 \pm 0 \cdot 3$ & $16 \cdot 1 \pm 0 \cdot 1 \dagger$ & $15 \cdot 6 \pm 0 \cdot 3$ \\
\hline Tibia length (mm) & $18 \cdot 1 \pm 0 \cdot 2$ & $18 \cdot 5 \pm 0 \cdot 3$ & $18 \cdot 2 \pm 0 \cdot 3$ & $17 \cdot 7 \pm 0 \cdot 2$ \\
\hline
\end{tabular}

Values are mean \pm S.E.M., $n=7-10$ mice per group. *Significantly different from sham-operated $(P<0 \cdot 05)$; $†$ significantly different from vehicle-treated $(P<0 \cdot 05)$ (ANOVA).

A

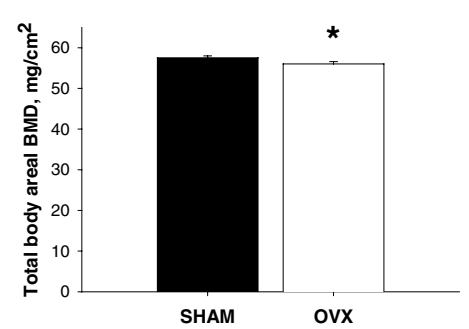

C

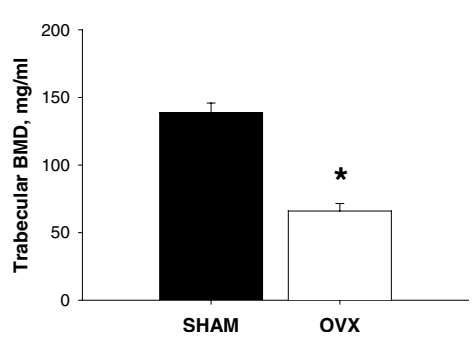

B

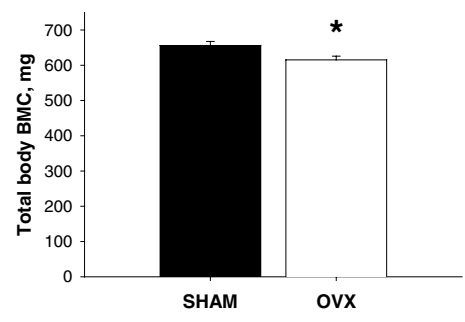

D

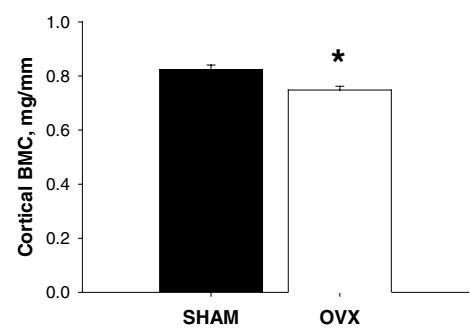

Figure 1 Effects of ovariectomy. Total body areal BMD (A), total body BMC (B), trabecular volumetric BMD (C) and cortical BMC (D) in sham-operated (SHAM) and ovx mice 6 weeks after surgery. Means \pm S.E.M., $n=17$. *Significantly different from sham-operated mice $(P<0 \cdot 05$, Student's $t$-test).

pQCT scans of the left femora were used to measure trabecular BMD. The metaphyseal scan was positioned at $3 \%$ of the total length of the femur proximal to the distal growth plate. The trabecular bone region was defined as the density of the inner $45 \%$ of the scanned bone area. Mid-diaphyseal pQCT scans of the left femora were used to determine the cortical BMD, the cortical cross-sectional area, the cortical thickness, the periosteal circumference, the endosteal circumference, the moment of resistance, and the cross-sectional moment of inertia. The inter-assay CVs for the pQCT measurements were less than $2 \%$.

It should be emphasized that DXA gives the areal $\mathrm{BMD}$, whereas the $\mathrm{PQCT}$ gives the real/volumetric BMD. Thus DXA gives the mineral content per area $\left(\mathrm{mg} / \mathrm{cm}^{2}\right)$, not per volume $(\mathrm{mg} / \mathrm{ml})$. Therefore, a factor regulating the outer dimensions of a bone will affect the areal BMD (DXA) but not the volumetric BMD (pQCT).

\section{Statistical analysis}

Results are presented as means \pm s.E.M., $n=7-10$. For analysis of the effects of ovariectomy before the start of drug treatment, the mice were pooled into two groups $(n=17$ each). Student's $t$-test was used to evaluate the effects of ovariectomy and the effect of drug treatment. $P<0.05$ was considered statistically significant. Data from excised bones were analyzed by one-way analysis of variance (ANOVA). Whenever statistically significant differences $(P<0 \cdot 05)$ were found between the experimental groups by ANOVA, individual differences were assessed by post hoc analysis (Tukey's test).

\section{Results}

Neither ovariectomy nor PTH treatment had any effects on body weight or the length of the tibia (Table 1). The 
A

Total body areal BMD

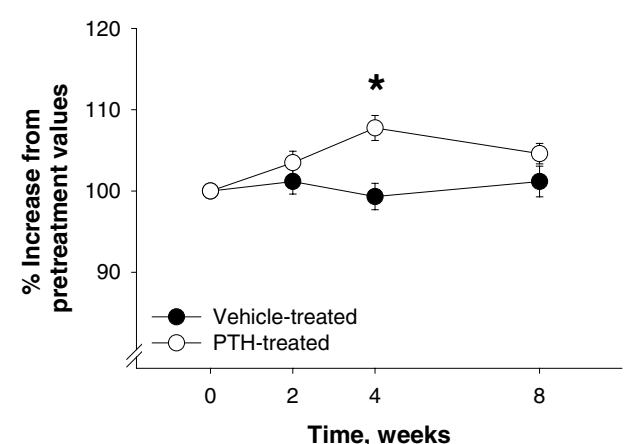

C

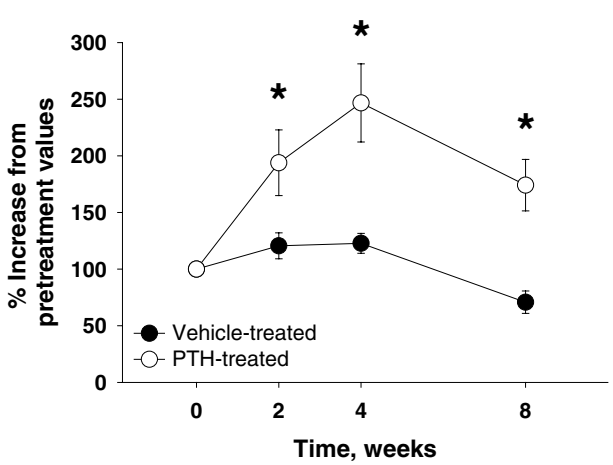

B

Total body BMC

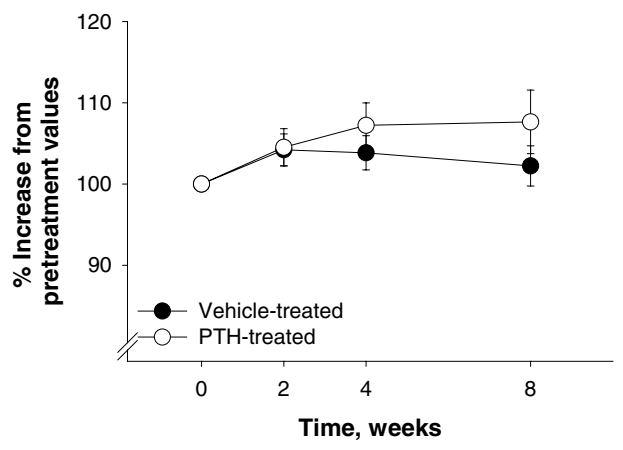

D

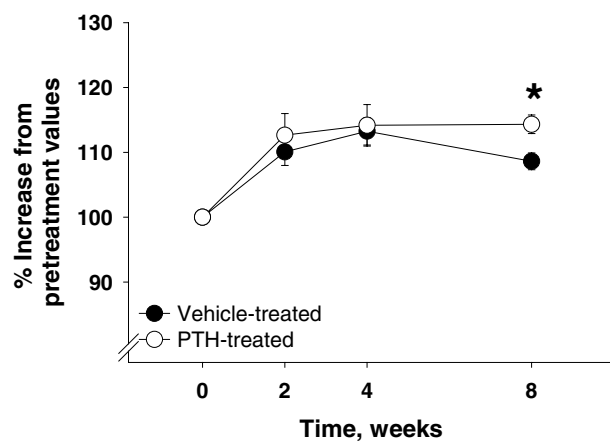

Figure 2 Effects of PTH treatment in ovx mice. The mice were ovariectomized 6 weeks before the start of treatment. Total body areal BMD $(A)$, total body $B M C(B)$, trabecular volumetric $B M D(C)$ and cortical BMC (D) were measured by DXA (A, B) and pQCT (C, D). Means \pm S.E.M., $n=7-10 .{ }^{*}$ Significantly different from vehicle-treated $(P<0 \cdot 05$, Student's $t$-test).

length of the femur was increased by $4 \pm 1 \%$ by PTH treatment in sham-operated mice, but no effect of PTH was found in ovx mice. Uterine weights were reduced in all ovx animals, confirming successful ovariectomy.

In vivo measurements of $\mathrm{BMD}$ were made at the start of PTH administration (6 weeks after ovariectomy) and 2, 4 and 8 weeks after the start of PTH treatment. Both DXA and $\mathrm{pQCT}$ scans were performed on each occasion.

Total body areal BMD and total body BMC were measured by DXA. At the start of treatment, 6 weeks after ovariectomy, total body areal BMD (Fig. 1A) and total body BMC (Fig. 1B) were decreased by $2.6 \pm 0.9 \%$ and $6 \cdot 2 \pm 1 \cdot 7 \%$ respectively, compared with the values for sham-operated mice. PTH treatment for 4 weeks increased total body areal BMD $(7 \cdot 7 \pm 1 \cdot 4 \%)$ compared with pretreatment values in ovx mice. However, after 8 weeks of treatment there was no statistically significant effect of PTH (Fig. 2A). PTH had no statistically significant effect on total body BMC in ovx mice (Fig. 2B). In shamoperated mice, PTH treatment had no significant effects on either total body areal BMD or total body BMC (Fig. 3A, B).

Trabecular BMD was measured by pQCT in the metaphysis of the tibia. The trabecular bone compartment was defined as the inner $45 \%$ of the scanned bone area. Six weeks after ovariectomy (i.e. at the start of PTH treatment), the trabecular volumetric BMD was decreased by $52 \pm 6.7 \%$ compared with that in sham-operated controls (Fig. 1C). Two weeks of PTH treatment increased the trabecular volumetric BMD compared with pretreatment values both in ovx and in sham-operated mice, by $94 \pm 29 \%$ and $46 \pm 10 \%$ respectively (Figs $2 \mathrm{C}$ and $3 \mathrm{C}$ ). In fact, the ovariectomy-evoked trabecular osteopenia was reversed after 4 weeks of PTH treatment (trabecular volumetric BMD in sham-operated vehicle-treated mice and ovx PTH-treated mice was $130 \pm 10 \mathrm{mg} / \mathrm{ml}$ and $120 \pm 12 \mathrm{mg} / \mathrm{ml}$, respectively).

The cortical BMC was determined in a mid-diaphyseal pQCT scan. Six weeks after ovariectomy, the cortical BMC was reduced by $9 \cdot 2 \pm 1.9 \%$ compared with that in the sham-operated animals (Fig. 1D). In ovx mice, PTH showed a statistically significant effect after 8 weeks of treatment (Fig. 2D). In contrast, no effect of PTH treatment was seen on cortical BMC in sham-operated mice (Fig. 3D).

Ex vivo DXA measurements were made on the excised femur, tibia and the fifth lumbar vertebra (L5). Ovx mice had lower BMC in the femur and the L5 than 


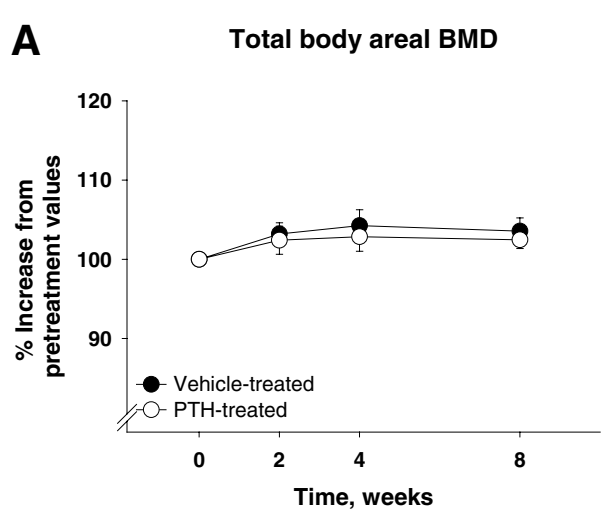

B Total body BMC
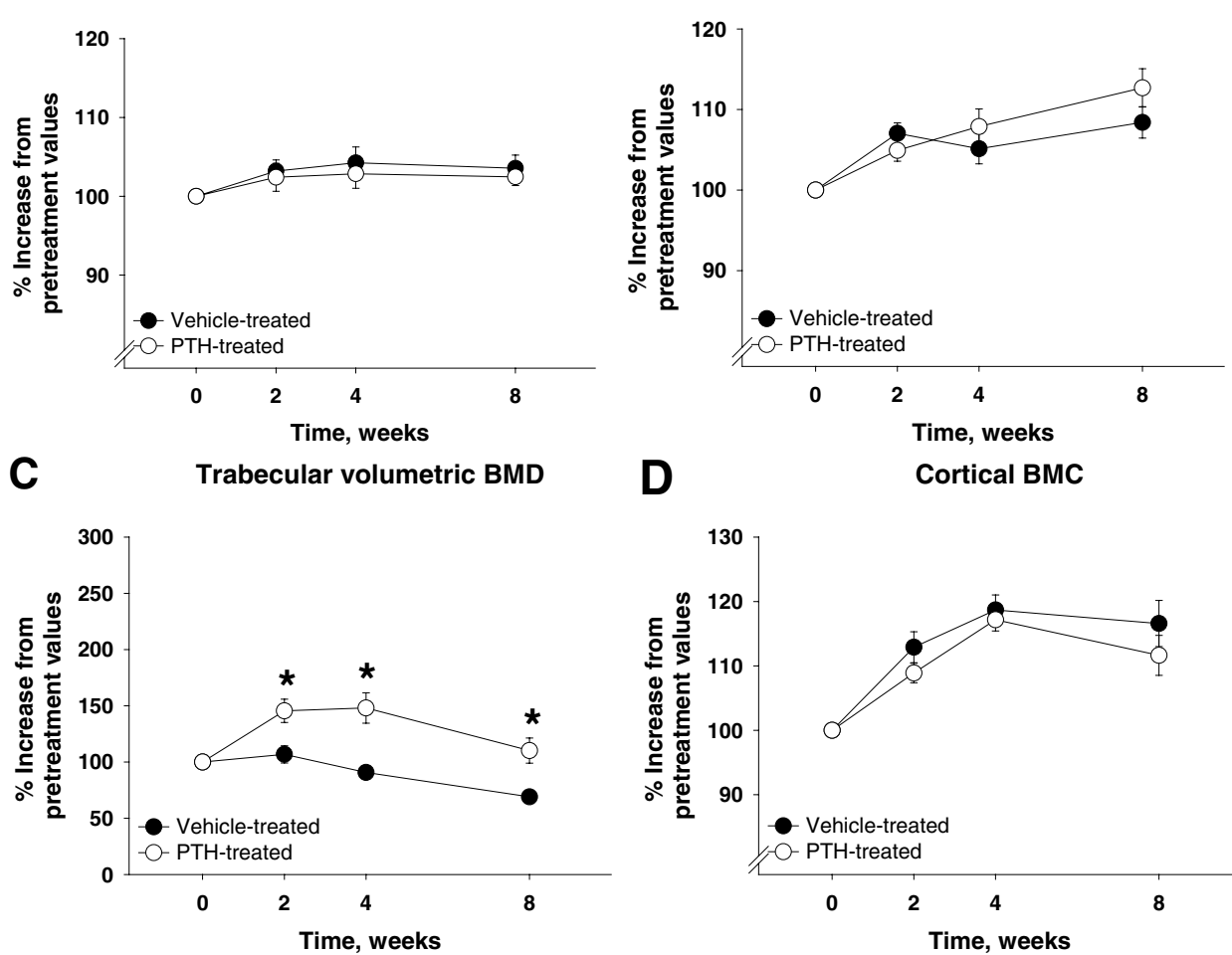

Figure 3 Effects of PTH treatment in sham-operated mice. The mice were sham-operated 6 weeks before the start of treatment. Total body areal BMD $(\mathrm{A})$, total body BMC $(\mathrm{B})$, trabecular volumetric $\mathrm{BMD}$ (C) and cortical BMC (D) were measured by DXA (A, B) and pQCT (C, D). Means \pm S.E.M., $n=8-9$.

${ }^{*}$ Significantly different from vehicle-treated $(P<0 \cdot 05$, Student's $t$-test).

sham-operated mice (femur $-19 \pm 2 \cdot 1 \%$ and L5 $-20 \pm 7 \cdot 6 \%$ compared sham-operated; Fig. 4). PTH treatment increased the BMC in the femur and in the L5 of ovx mice ( $20 \pm 2 \cdot 7 \%$ and $24 \pm 7 \cdot 6 \%$ respectively). PTH treatment also increased the BMC in the femur of sham-operated mice $(10 \pm 1 \cdot 7 \%)$. Neither ovariectomy nor PTH treatment had any statistically significant effect on BMC of the intact tibia (Fig. 4).

High-resolution (line spacing $0.01 \mathrm{~cm}$ ) DXA scans were also performed on one representative femur and the L5 from one animal in each group. The scans confirmed the pronounced effects of both ovariectomy and PTH treatment (Fig. 5).

\section{Discussion}

It is well known that ovariectomy results in a reduced BMC mainly because of a decrease in trabecular bone, whereas PTH treatment reverses the trabecular bone loss. Most studies on this subject have been performed using traditional methods including ash weight (BMC) and histomorphometry. These techniques are well established and useful for the determination of bone mass and bone quality in killed animals. However, they are labourintensive and not possible to perform longitudinally without killing a relatively large number of mice at each time point. DXA and pQCT might be useful tools with which to determine the phenotype of new genetically modified mice and for estimating treatment effects during drug treatment. We have previously demonstrated that DXA determinations of BMC in mice correlate well with BMC as measured by ash weight (Sandstedt et al. 1996) and that trabecular volumetric BMD estimated using pQCT correlate well with bone volume/total volume as measured by histomorphometry (Windahl et al. 2001).

In the present study, 6-week-old female mice underwent ovariectomy or were sham-operated. The mice were then treated with PTH intermittently for 8 weeks, and the bone mineral was followed longitudinally in vivo by repeated measurements using both DXA and $\mathrm{pQCT}$. The dose of PTH used in the present study (PTH(1-84) $150 \mu \mathrm{g} / \mathrm{kg}$ per day) was chosen because it has been shown to reverse the effect of ovariectomy in rats (Andersson et al. 1998). In the present study, we used $150 \mu \mathrm{g} / \mathrm{kg}$ per day PTH(1-84), whereas most previous studies used PTH(134). The equimolar amount of $\mathrm{PTH}(1-34)$ would be $66 \mu \mathrm{g} / \mathrm{kg}$ per day. In vivo studies directly comparing the 
A

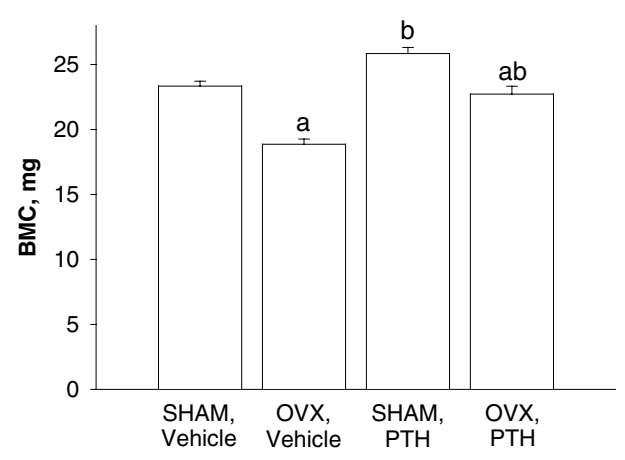

B

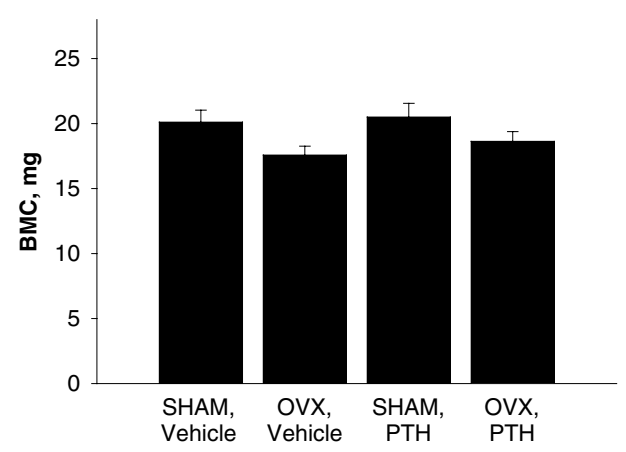

C

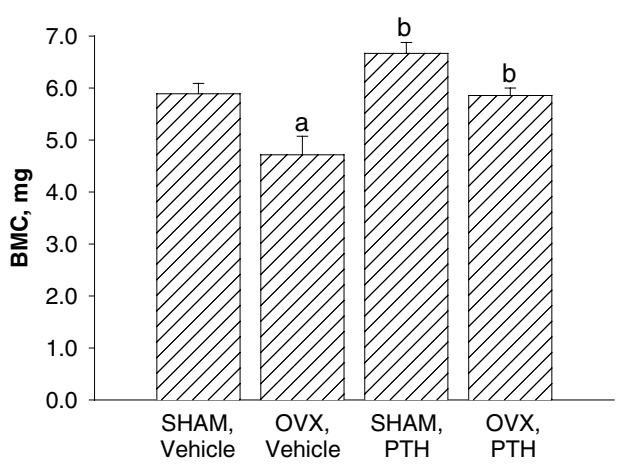

Figure 4 Bone mineral content (BMC) measured ex vivo in the femur (A), tibia (B) and vertebra L5 (C) after 8 weeks of PTH treatment in ovx and sham-operated (SHAM) mice. BMC was measured by DXA; all bones that were compared were present in a single scan. Means \pm S.E.M., $n=7-10$. a Significantly $(P<0 \cdot 05)$ different from sham-operated; ${ }^{b}$ significantly $(P<0 \cdot 05)$ different from vehicle-treated (ANOVA).

effects of human $\mathrm{PTH}(1-34)$ and human $\mathrm{PTH}(1-84)$ found that the two peptides at equimolar doses increased the bone mass to a similar extent in rats (Mosekilde et al. 1991, Ejersted et al. 1993, Kimmel et al. 1993). Little information is yet available as to the in vivo effect of $\mathrm{PTH}$ in mice (Rihani-Bisharat et al. 1998, Zeng et al. 1998). However, the two peptides appear to be equipotent in mice also (Stanislaus et al. 2000).

Ovariectomy in the rat is associated with an increase in body weight (Wronski et al. 1987). Existing data on the effect of ovariectomy on the body weight in mice are inconsistent: one study has shown that ovariectomy results in an increased body weight (Bain et al. 1993), whereas other reports have failed to do so (Edwards et al. 1992, Sandstedt et al. 1996, Yoshitake et al. 1999). No significant effect on body weight was seen in the present study. Successful ovariectomy was confirmed by a significant decrease in uterine weights. In the present study we used young (but sexually mature) mice, whereas older mice were used in previous studies. This difference may, at least partly, explain the difference with respect to body weight gain after ovariectomy.

Total body BMC and total body areal BMD were measured by DXA at regular intervals throughout the study. Ovariectomy resulted both in reduced total body BMC and reduced total body areal BMD. In ovx mice, DXA revealed statistically significant PTH-evoked treatment effects on total body areal BMD only after 4 weeks, whereas no effect was seen after 8 weeks of treatment. No other treatment-evoked effects on total body areal BMD or on total body BMC were detected by DXA in ovx and sham-operated mice in vivo. Ex vivo, the excised bones were measured by DXA. These measurements revealed effects of PTH treatment on BMC in the femur and vertebrae L5 of both ovx and sham-operated mice. In a DXA scan, the areal BMD is a presentation of the bone mineral content (BMC) per bone area. As the cortical bone represents about $80 \%$ of the bone mass in humans (Ma et al. 1999), the amount of cortical bone in a mouse is likely to be more than $95 \%$. Trabecular and cortical bone can not be separated by DXA. Therefore, most of the total body areal BMD and total body BMC, as measured by DXA, is accounted for by cortical bone. Thus the relatively low trabecular bone content in mice may explain the small effect of ovariectomy on total body areal BMD and total body BMC. Detection of treatment effects of an anabolic agent such as PTH, which mainly acts on trabecular bone, will therefore be difficult using the DXA technique in mice. If the DXA scan is performed on excised bones that contain a relatively larger amount of trabecular bone, such as a vertebra, the treatment effects will become more pronounced. As discussed above, some of the effects of PTH treatment in the present study were detected by DXA on the excised bones, but not by the in vivo measurements. The inter-scan variations between different DXA scans of mice in vivo are another problem. In the in vivo measurements, an internal standard was included in each scan to reduce this variation. This 
Table 2 Trabecular volumetric BMD and cortical bone parameters measured in the femur by pQCT. Measurements were performed ex vivo after 8 weeks of intermittent PTH treatment

\begin{tabular}{|c|c|c|c|c|}
\hline & $\begin{array}{l}\text { Sham } \\
\text { Vehicle }\end{array}$ & $\begin{array}{l}\text { Ovx } \\
\text { Vehicle }\end{array}$ & $\begin{array}{l}\text { Sham } \\
\text { PTH }\end{array}$ & $\begin{array}{l}\text { Ovx } \\
\text { PTH }\end{array}$ \\
\hline Trabecular BMD (mg/ml) & $87 \pm 13$ & $42 \pm 12$ & $171 \pm 18 \dagger$ & $84 \pm 16^{*}$ \\
\hline Cortical BMC (mg/mm) & $1 \cdot 02 \pm 0 \cdot 02$ & $0 \cdot 81 \pm 0 \cdot 01^{*}$ & $1.03 \pm 0.03$ & $0.93 \pm 0.03^{*} \dagger$ \\
\hline Cortical BMD (mg/ml) & $1116 \pm 7$ & $1152 \pm 7^{*}$ & $1121 \pm 9$ & $1085 \pm 5^{*} \dagger$ \\
\hline Cortical area $\left(\mathrm{mm}^{2}\right)$ & $0 \cdot 86 \pm 0 \cdot 02$ & $0 \cdot 72 \pm 0 \cdot 01^{*}$ & $0 \cdot 87 \pm 0 \cdot 02$ & $0 \cdot 80 \pm 0 \cdot 02 \dagger$ \\
\hline Periosteal circumference $(\mathrm{mm})$ & $5 \cdot 001 \pm 0 \cdot 042$ & $4 \cdot 761 \pm 0 \cdot 036^{*}$ & $4 \cdot 963 \pm 0 \cdot 043$ & $4 \cdot 821 \pm 0 \cdot 080$ \\
\hline Endosteal circumference $(\mathrm{mm})$ & $3 \cdot 774 \pm 0 \cdot 046$ & $3 \cdot 686 \pm 0 \cdot 033$ & $3 \cdot 701 \pm 0 \cdot 044$ & $3 \cdot 632 \pm 0.076$ \\
\hline Cortical thickness (mm) & $0 \cdot 195 \pm 0 \cdot 004$ & $0 \cdot 171 \pm 0 \cdot 001^{*}$ & $0 \cdot 200 \pm 0 \cdot 005$ & $0 \cdot 189 \pm 0 \cdot 003 \dagger$ \\
\hline Moment of resistance $\left(\mathrm{mm}^{3}\right)$ & $0 \cdot 389 \pm 0 \cdot 015$ & $0 \cdot 282 \pm 0 \cdot 010^{*}$ & $0 \cdot 384 \pm 0 \cdot 017$ & $0 \cdot 326 \pm 0.023 \dagger$ \\
\hline Moment of inertia $\left(\mathrm{mm}^{4}\right)$ & $0 \cdot 396 \pm 0 \cdot 013$ & $0 \cdot 307 \pm 0 \cdot 007^{*}$ & $0 \cdot 398 \pm 0 \cdot 014$ & $0 \cdot 335 \pm 0 \cdot 14^{*}$ \\
\hline
\end{tabular}

Values are mean \pm S.E.M., $n=7-9$ mice per group. *Significantly different from sham-operated $(P<0 \cdot 05)$; $†$ significantly different from vehicle-treated $(P<0 \cdot 05)$ (ANOVA).

limited the number of mice that could be scanned at the same time. In the ex vivo measurements, however, all bones were scanned at the same time and inter-scan variation was avoided.

The pQCT technique measures the true volumetric $\mathrm{BMD}$, and it may be used to measure trabecular and cortical bone separately. Trabecular volumetric BMD can be measured in the central part of the metaphysis of the distal femur and proximal tibia. Ovariectomy resulted in a markedly decreased trabecular volumetric BMD, confirm-

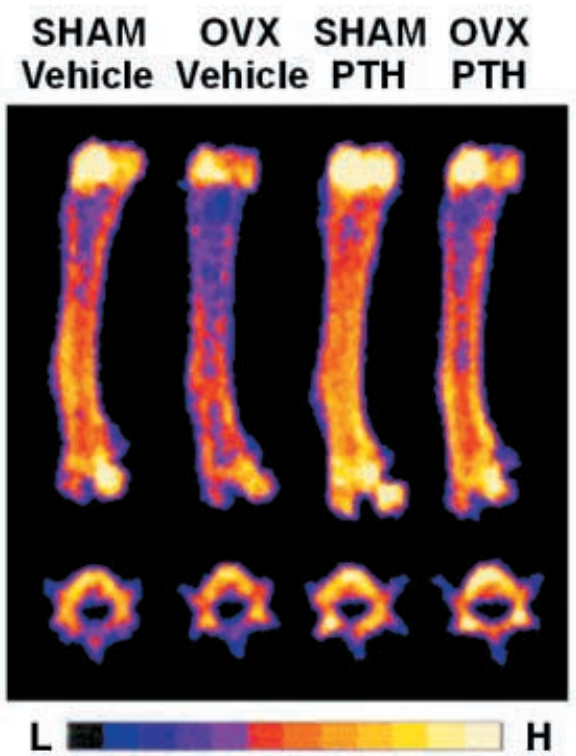

Figure 5 High-resolution DXA scan of the femur (top) and vertebra L5 (bottom) from one representative animal in each of the drug treatment groups. The relative areal BMD is indicated: $\mathrm{H}=$ high areal $\mathrm{BMD} ; \mathrm{L}=$ low areal $\mathrm{BMD}$. ing the findings of a recent study in which the same technique was used in mice (Windahl et al. 1999).

Notably, the pQCT - but not the DXA - technique detected a pronounced effect of PTH on trabecular bone as soon as after 2 weeks of treatment. After the animal was killed, the femur was excised and the trabecular volumetric $\mathrm{BMD}$ was measured in the metaphysis of the distal femur. The trabecular volumetric BMD in the excised femurs was very similar to that obtained in vivo in the metaphysis of the proximal tibia, suggesting that the trabecular bone in the metaphyseal region of the proximal tibia reflects the trabecular bone at other locations also.

The effects of ovariectomy and PTH treatment on cortical bone were studied by pQCT in the diaphysis of the tibia and femur. Estrogen-deficient rats have been reported to have decreased cortical BMC (Yamazaki \& Yamaguchi 1989), whereas PTH has been shown to exert anabolic effects on cortical bone (Dempster et al. 1993). Mid-diaphyseal pQCT scans on excised bones revealed that the cortical BMC, the cortical cross-sectional area and the cortical thickness were reduced after ovariectomy in both the femur (Table 2) and the tibia. The effects of ovariectomy were counteracted by 8 weeks of PTH treatment. This means that the effect of PTH on cortical bone of mice was similar to that reported in the rat (Wronski \& Yen 1994). In contrast, no effect on cortical bone of PTH treatment was seen in sham-operated mice. Thus PTH treatment resulted in a pronounced and fast increase in the trabecular volumetric BMD in both ovx and sham-operated mice. In contrast, a statistically significant effect of PTH on cortical bone was only detected in ovx mice. It was, however, both delayed and less pronounced.

Both DXA and pQCT are equally time-consuming and labour-intensive. One disadvantage with the DXA equipment used in the present study was a relatively large between-scan variation in the in vivo measurements (see 
above). The advantage of DXA compared with $\mathrm{pQCT}$ is the possibility of measuring the dimensions and the $\mathrm{BMC}$ both in the total body and in individual bones. One important disadvantage of using DXA for determination of bone mass is that it provides a picture of an attenuated $\mathrm{X}$-ray passing though the body; accordingly, the picture obtained is two-dimensional (areal BMD, $\mathrm{g} / \mathrm{cm}^{2}$ ). DXA therefore only recognizes changes in width and length, but does not account for changes in the third dimension. The major advantage of pQCT over DXA is the ability to examine a specific bone compartment. Thus cortical bone and trabecular bone can be analyzed separately. Furthermore, the between-scan variations are small in the pQCT measurements.

In conclusion, the pQCT technique is more sensitive than the DXA technique in the detection of bone loss after ovariectomy and increased bone mass after PTH treatment in mice. PTH treatment resulted in a pronounced and fast increase in trabecular volumetric BMD, whereas a less pronounced and later effect was seen on the cortical bone. Notably, the pQCT - but not the DXA - technique detected a pronounced effect as early as after 2 weeks of PTH treatment. Therefore dynamic in vivo measurements, using pQCT, are useful for the monitoring of skeletal changes in mice.

\section{Acknowledgements}

The authors are grateful to Mrs Susanne Arvidsson, Mrs Agneta Karlsson and Mrs Dorota Kakol-Palm for their expert technical assisstance.

\section{References}

Andersson N, Kakol-Palm D, Arvidsson S, Ohlsson C, Sjögren S, Andersson K \& Ryberg B 1998 Human parathyroid hormone, hPTH(1-84) - effect in distal femur following intermittent or continious administration in rats. Bone 23 (Suppl) SA450.

Bagi CM, Ammann P, Rizzoli R \& Miller SC 1997 Effect of estrogen deficiency on cancellous and cortical bone structure and strength of the femoral neck in rats. Calcified Tissue International 61 336-344.

Bain SD, Jensen E, Celino DL, Bailey MC, Lantry MM \& Edwards MW 1993 High-dose gestagens modulate bone resorption and formation and enhance estrogen-induced endosteal bone formation in the ovariectomized mouse. Journal of Bone and Mineral Research 8 219-230.

Broulik PD 1991 Tamoxifen prevents bone loss in ovariectomized mice. Endocrine Regulations 25 217-219.

Dempster DW, Cosman F, Parisien M, Shen V \& Lindsay R 1993 Anabolic actions of parathyroid hormone on bone [published erratum appears in Endocrine Reviews 199415 261]. Endocrine Reviews 14 690-709.

Dempster DW, Cosman F, Parisien M, Shen V \& Lindsay R 1995 Anabolic actions of parathyroid hormone on bone: update 1995 . Endocrine Reviews 4 247-250.

Edwards MW, Bain SD, Bailey MC, Lantry MM \& Howard GAO 199217 Beta estradiol stimulation of endosteal bone formation in the ovariectomized mouse: an animal model for the evaluation of bone-targeted estrogens. Bone 13 29-34.
Ejersted C, Andreassen TT, Oxlund H, Jorgensen PH, Bak B, Haggblad J, Torring O \& Nilsson MH 1993 Human parathyroid hormone (1-34) and (1-84) increase mechanical strength and thickness of cortical bone in rats. Journal of Bone and Mineral Research 8 1097-1101.

Kimmel DB, Bozzato RP, Kronis KA, Coble T, Sindrey D, Kwong P \& Recker RR 1993 The effect of recombinant human (1-84) or synthetic human (1-34) parathyroid hormone on the skeleton of adult osteopenic ovariectomized rats. Endocrinology 132 15771584.

Li X, Takahashi M, Kushida K, Koyama S, Hoshino H, Kawana K, Horiuchi K \& Inoue T 1996 The effect of tamoxifen on bone metabolism and skeletal growth is different in ovariectomized and intact rats. Calcified Tissue International 59 271-276.

Ma Y, Jee WSS, Yuan Z, Wei W, Chen H, Pun S, Liang H \& Lin C 1999 Parathyroid hormone and mechanical usage have a synergistic effect in rat tibial diaphyseal cortical bone. Journal of Bone and Mineral Research 14 439-448.

Mitlak BH, Burdettemiller P, Schoenfeld D \& Neer RM 1996 Sequential effects of chronic human PTH (1-84) treatment of estrogen-deficiency osteopenia in the rat. Journal of Bone and Mineral Research 11 430-439.

Mosekilde L, Sogaard CH, Danielsen CC \& Torring O 1991 The anabolic effects of human parathyroid hormone (hPTH) on rat vertebral body mass are also reflected in the quality of bone, assessed by biomechanical testing: a comparison study between hPTH-(1-34) and hPTH-(1-84). Endocrinology 129 421-428.

Okada Y, Morimoto I, Ura K, Nakano Y, Tanaka Y, Nishida S, Nakamura T \& Eto S 1998 Short-term treatment of recombinant murine interleukin-4 rapidly inhibits bone formation in normal and ovariectomized mice. Bone 22 361-365.

Reeve J, Hesp R, Williams D, Hulme P, Klenerman L, Zanelli JM, Darby AJ, Tregear GW \& Parsons JA 1976 Anabolic effect of low doses of a fragment of human parathyroid hormone on the skeleton in postmenopausal osteoporosis. Lancet 1 1035-1038.

Reeve J, Meunier PJ, Parsons JA, Bernat M, Bijvoet OL, Courpron P, Edouard C, Klenerman L, Neer RM, Renier JC, Slovik D, Vismans FJ \& Potts JT Jr 1980 Anabolic effect of human parathyroid hormone fragment on trabecular bone in involutional osteoporosis: a multicentre trial. British Medical Journal 280 1340-1344.

Rihani-Bisharat S, Maor G \& Lewinson D 1998 In vivo anabolic effects of parathyroid hormone (PTH) 28-48 and N-terminal fragments of PTH and PTH-related protein on neonatal mouse bones. Endocrinology 139 974-981.

Rosen HN, Tollin S, Balena R, Middlebrooks VL, Beamer WG, Donohue LR, Rosen C, Turner A, Holick M \& Greenspan SL 1995 Differentiating between orchiedectomized rats and controls using measurements of trabecular bone density: a comparison among DXA, histomorphometry, and peripheral quantitative computerized tomography. Calcified Tissue International 57 35-39.

Sandstedt J, Törnell J, Norjavaara E, Isaksson OG \& Ohlsson C 1996 Elevated levels of growth hormone increase bone mineral content in normal young mice, but not in ovariectomized mice. Endocrinology $1373368-3374$.

Sato M, Zeng GQ \& Turner CH 1997 Biosynthetic human parathyroid hormone (1-34) effects on bone quality in aged ovariectomized rats. Endocrinology 138 4330-4337.

Shen V, Birchman R, Xu R, Otter M, Wu D, Lindsay R \& Dempster DW 1995 Effects of reciprocal treatment with estrogen and estrogen plus parathyroid hormone on bone structure and strength in ovariectomized rats. Journal of Clinical Investigation 96 2331-2338.

Stanislaus D, Devanarayan V \& Hock JM 2000 In vivo comparison of activated protein-1 gene activation in response to human parathyroid hormone $(\mathrm{hPTH})(1-34)$ and $\mathrm{hPTH}(1-84)$ in the distal femur metaphyses of young mice. Bone 27 819-826. 
Turner RT, Vandersteenhoven JJ \& Bell N 1987 The effects of ovariectomy and $17 \beta$-estradiol on cortical bone histomorphometry in growing mice. Journal of Bone and Mineral Research 2 115-122.

Windahl SH, Vidal O, Andersson G, Gustafsson JA \& Ohlsson C 1999 Increased cortical bone mineral content but unchanged trabecular bone mineral density in female ER $\beta$-/- mice. Journal of Clinical Investigation 104 895-901.

Windahl SH, Hollberg K, Vidal O, Gustafsson J-Å, Ohlsson C \& Andersson G 2001 Female estrogen receptor- $\beta$-/- mice are partially protected against age-related trabecular bone loss. Journal of Bone and Mineral Research (In Press).

Wronski TJ \& Yen C-F 1994 Anabolic effects of parathyroid hormone on cortical bone in ovariectomized rats. Bone 15 51-58.

Wronski TC, Schenck PA, Cintrón M \& Walsh CC 1987 Effect of body weight on osteopenia in ovariectomized rats. Calcified Tissue International 40 155-159.
Yamauchi H, Kushida K, Yamazaki K \& Inoue T 1995 Assessment of spine bone mineral density in ovariectomized rats using DXA. Journal of Bone and Mineral Research 10 1033-1039.

Yamazaki I \& Yamaguchi H 1989 Characteristics of an ovariectomized osteopenic rat model. Journal of Bone and Mineral Research 4 13-22.

Yoshitake H, Rittling SR, Denhart DT \& Noda M 1999 Osteopontin-deficient mice are resistant to ovariectomy-induced bone resorption. PNAS 96 8156-8160.

Zeng GQ, Cole HW, Smith SJ, Bryant HU \& Sato M 1998 Bone effects in mice of ovariectomy and recombinant human PTH (1-34) are highly strain dependent. Bone 23 (Suppl) S448.

Received 20 April 2001

Accepted 30 May 2001 